\title{
A Case of Diagnostic Dilemma - LCH
}

\author{
Jyoti Arora', Pankaj Mehta ${ }^{2}$, Vijay Kumar Roy', Vandita Sharma ${ }^{3}$, Amit Kumar ${ }^{4}$ \\ ${ }^{1}$ Associate Professor, Department of Physiology, SGT Medical College, Gurugram (Haryana)-122505, ${ }^{2}$ Consultant Paediatrician, Sheetla Hospital, Gurugram \\ (Haryana)-122001, ${ }^{3}$ Director, Sheetla Hospital, Gurugram (Haryana)-122001, ${ }^{4} \mathrm{Head}$ of the Department, Department of Paediatrics, Sheetla Hospital, Gurugram \\ (Haryana)-122001.
}

\section{Abstract}

LCH in the skin, bones, lymph nodes or pituitary gland usually gets better with treatment and is called low-risk. Some patients have involvement in the spleen, liver, bone marrow, lung and skeleton. This is called high-risk disease and may be more difficult to treat. This study was conducted in the Department of Physiology, SGT Medical College, Gurugram (Haryana). The result of this study revealed that Hepatitis along with above findings suggestive of langerhans cell histiocytosis. So this diagnosis was made in advanced stage of disease. This case had all the typical findings (symptoms \& signs), but even then it took considerable time to come to the correct diagnosis of advanced stage of langerhans cell histiocytosis. Though presenting rarely, this case was interesting enough to discuss.

Keywords: LCH, Dilemma, Histiocytosis, risk organs.

Corresponding Author: Dr. Jyoti Arora, H. No. 808, Sector 9, Gurugram (Haryana) - 122001.

Received: August 2019

Accepted: August 2019

\section{Introduction}

Histiocytosis was first described in the medical literature in the mid to late 1800s. Through the years, it has been known by various names, such as histiocytosis $\mathrm{X}$, eosinophilic granuloma, Letterer-Siwe disease, Hashimoto-Pritzker disease, and Hand-Schüller-Christian syndrome. In 1973, the name Langerhans cell histiocytosis ( $\mathrm{LCH}$ ) was introduced. ${ }^{[1]}$

The prevalence of Langerhans cell histiocytosis (LCH) seems to be higher among whites than in persons of other races. $^{[2]}$

The frequency of Langerhans cell histiocytosis $(\mathrm{LCH})$ is greater in males than in females, with a male-to-female ratio of $2: 1 .^{[3,4]}$

LCH is believed to occur in 1:200,000 children, but any age group can be affected, from infancy through adulthood (reportedly approximately 4 cases per million population). ${ }^{[5]}$

\section{The age at onset varies according to the variant of $\mathrm{LCH}$,} as follows:

- Letterer-Siwe disease occurs predominantly in children younger than 2 years.

- The chronic multifocal form, including Hand-SchüllerChristian syndrome, has a peak of onset in children aged 210 years.

- Localized eosinophilic granuloma occurs mostly frequently in children aged 5-15 years.

- Pulmonary LCH is more common during the third and fourth decades of life. ${ }^{[6]}$

It occurs most often between the ages of 1-3 years and may appear as a single lesion or can affect many body systems, such as skin, bone, lymph glands, liver, lung, spleen, brain, pituitary gland and bone marrow. ${ }^{[1]}$

Information has been collected in various studies which show that bone involvement occurs in approximately $78 \%$ of patients with LCH and often includes the skull (49\%), hip/pelvic bone (23\%), upper leg bone (17\%) and ribs (8\%). Skin LCH is seen in as many as $50 \%$ of patients. Lung lesions are seen in $20 \%$ to $40 \%$ of patients, while $30 \%$ of patients have lymph node involvement. ${ }^{[1]}$

Symptoms depend on the location and severity of involvement. It is usually diagnosed with a tissue biopsy, in addition to other testing, such as X-rays and blood studies. A biopsy of an involved site is necessary to make a definitive diagnosis. $^{[1]}$

LCH in the skin, bones, lymph nodes or pituitary gland usually gets better with treatment and is called "low-risk." Some patients have involvement in the spleen, liver, bone marrow, lung and skeleton. This is called "high-risk disease" and may be more difficult to treat. ${ }^{[1]}$

Certain factors affect the chance of recovery and options for treatment. These factors include the extent of the disease, whether "risk organs" (liver, spleen, lung, bone marrow) are involved, and how quickly the disease responds to initial treatment. ${ }^{[1]}$

Langerhans cell histiocytosis (also called histiocytosis $\mathrm{X}$ ) is a rare disorder that primarily affects children. This disorder is characterized by an abnormal increase in certain immune cells called histiocyte cells. Histiocyte cells are a form of white blood cells that help the immune system destroy foreign materials and fight infection. The extra immune cells produced by this condition may form tumors, which can affect parts of the body like the bones and possibly 
spread to other areas as well. ${ }^{[7]}$

Langerhans cell histiocytosis historically was thought of as a cancer-like condition, but more recently researchers have begun to consider it an autoimmune phenomenon in which immune cells begin to overproduce and attack the body instead of fighting infection. In most cases, it is not known why the disorder appears, although there may be a genetic link. However, it is not contagious; people with Langerhans cell histiocytosis cannot spread the disorder to others. ${ }^{[7]}$ Most cases affect children between 1 and 15 years old, with the majority of new cases in children between 5 and $10 .{ }^{[7]}$ In children, Langerhans cell histiocytosis may involve only one part of the body or many different sites. ${ }^{[7]}$

\begin{tabular}{|l|l|}
\hline Site & Possible Symptoms \\
\hline Skin & General rash, Dandruff \\
\hline Bone & Lesions, bone pain, limping \\
\hline Lung, liver, spleen & Dysfunction \\
\hline Teeth and gums & Loose or lost teeth, swollen gums \\
\hline Ear & Chronic infections/Discharge \\
\hline Eyes & Vision problems or bulging eyes \\
\hline Central nervous system & $\begin{array}{l}\text { Headache, dizziness, vomiting, excessive } \\
\text { thirst, frequent urination }\end{array}$ \\
\hline General symptoms & $\begin{array}{l}\text { Fever, weakness, fatigue, irritability, } \\
\text { swollen lymph glands, failure to gain } \\
\text { weight }\end{array}$ \\
\hline
\end{tabular}

Not all patients will have every one of these symptoms. And because these symptoms could be caused by another condition, not related to Langerhans cell histiocytosis, it is important to seek proper medical attention to receive an accurate diagnosis. ${ }^{[7]}$

The working group of the Histiocyte Society has divided histocytic disorders into 3 groups: (1) dendritic cell histiocytosis, (2) macrophage-related disorders, and (3) malignant histiocytosis. ${ }^{[8]}$

LCH belongs in group 1 and encompasses a number of diseases. On one end, the clinical spectrum includes an acute, fulminant, disseminated disease called Letterer-Siwe disease, and, on the other end, solitary or few, indolent and chronic lesions of bone or other organs called eosinophilic granulomas. The intermediate clinical form called HandSchüller-Christian disease is characterized by multifocal, chronic involvement and classically presents as the triad of diabetes insipidus, proptosis, and lytic bone lesions. A congenital, self-healing form called Hashimoto-Pritzker disease has also been described. ${ }^{[2]}$

\section{Case Report}

A boy of age 3 years, resident of Gurgaon, presented with complaint of loose stools, for last 5-6 days, progressive abdominal distension, increased urine output and also increased water intake for last 1 month.

On general physical examination- pallor present, weight was $9 \mathrm{kgs}$.

\section{On systemic examination-}

Chest/CVS Examination- normal

Per abdomen - abdomen distended, liver was found to be somewhat enlarged, $2 \mathrm{~cm}$; spleen palpable.

So patient was advised fluid restriction \& was treated with multivitamins/ haemtinics / d--3 drops for FTT (Failure To Thrive).

\section{Advised CBC/ RBS/ urinary r/m (routine microscopy).}

S.Bilirubin- 4.20/3.18 (D) (direct) $\mathrm{mg} \%$.

Patient came after 1 week with repeated vomiting / yellowish discoloration of sclera/ passage of dark colored urine. The history of increased urine output was still present. Then the patient was admitted with above mentioned complaints with probable diagnosis of acute hepatitis and polyuria.

\section{Other examination}

Per abdomen -distended, liver --3 cm, tender; spleen-not palpable

Investigation - CBC (complete blood count)/ LFT (liver function test)/ KFT (kidney function test) were done.

\section{Repeated LFTs show}

S. Bilirubin=4.20 mg \%/ $3.18 \mathrm{mg} \%$ (D), SGOT/PT (serum glutamate oxaloacetate transferase/ pyruvate transferase) $=47.8 / 42.3 \mathrm{IU} / \mathrm{L}$ (International units per liter), S. ALK PO4 (serum alkaline phosphotase $)=1144 \mathrm{IU} / \mathrm{L}$

$\mathrm{S}$. Bilirubin=4.16 mg \% $/ 3.05 \mathrm{mg} \%$ (D), SGOT/PT $=41.7$ 134.9 IU/L, S.ALK PO4=1139 IU/L.

S. Bilirubin=5.27/4.07, SGOT/PT =41.7/34.9 IU/L, S. ALK PO4=826 IU/L

S. Amylase/ S. Lipase -wnl (within normal limits)

All viral markers of hepatitis --HBs Ag (Hepatitis B antigen) / HCV (Hepatitis B virus) / Anti--HAV -Ig M (Hepatitis A virus) /Anti --HEV-Ig M (Hepatitis E virus) -non-reactive.

Now there are two main issues- persistently deranged LFT \& polyuria.

For polyuria, S.ADH level was investigated and was found to be $<0.50 \mathrm{pmol} / 1$---v.low (normal value 0.50 to 13.00 $\mathrm{pmol} / \mathrm{l})$.

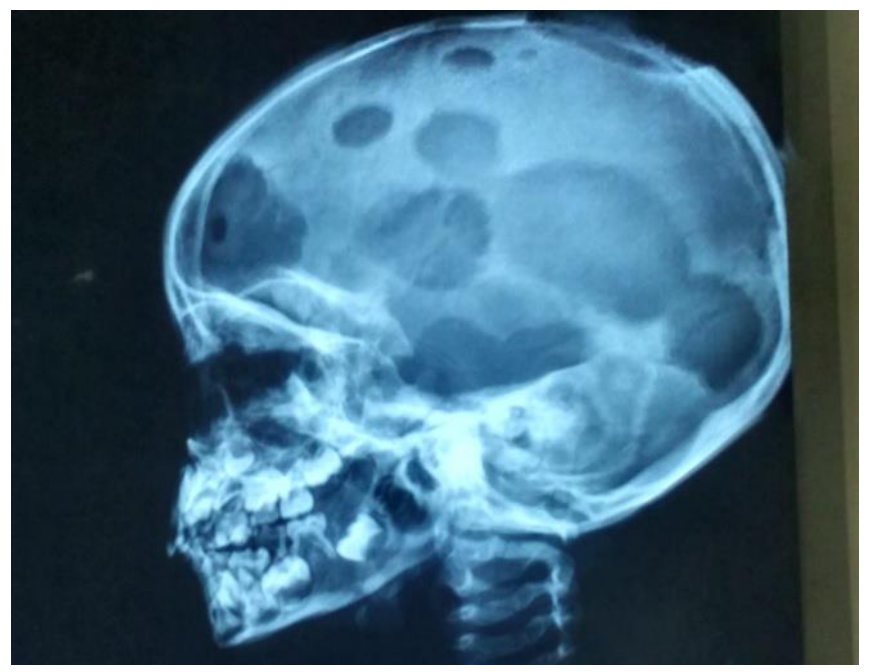

Figure 1: X-Ray skull in lateral view showing various punched out lesions in skull. 


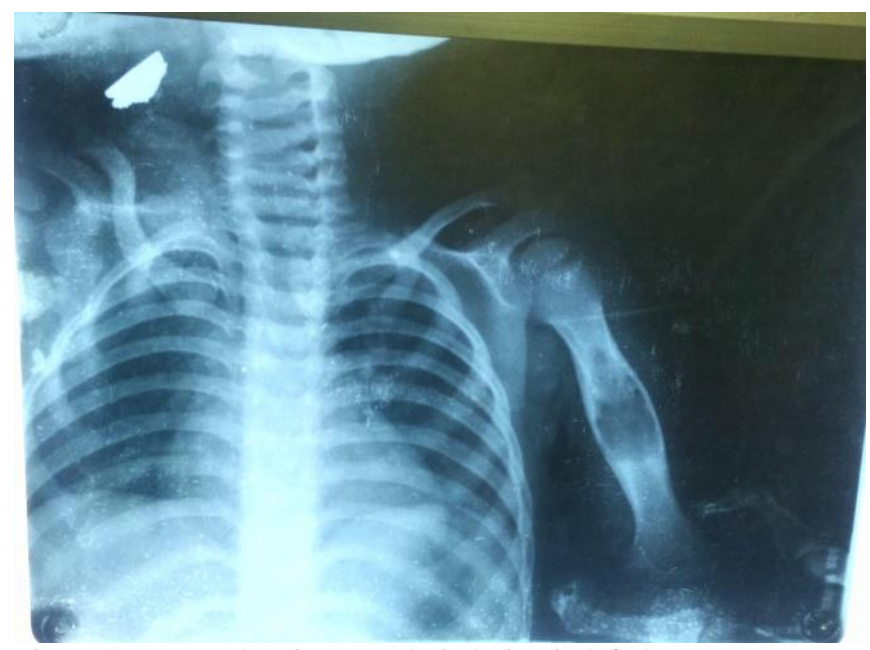

Figure 2: X-Ray showing osteolytic lesion in left humerus.

S.Osmolality was found to be $319 \mathrm{mosm} / \mathrm{kg}$ body weights.

Past History --Patient also complaint of some osteolytic lesion over clavicle (Patient taking ATT -anti-tubercular treatment, for osseous tuberculosis diagnosed at a private hospital, Delhi.)

Now history dates back to 1 year back.

Patient had developed swelling over humerus with lytic lesions of bone \& proximal tibia alongwith painful movements.

He had been advised biopsy of affected site alongwith symptomatic treatment.

Biopsy from humerus --revealed lytic lesions comprising of many osteoblastic giant cells, with stromal cells, alongwith acute inflammatory exudates with some old hemorrhages --suggestive of giant cell tumor.

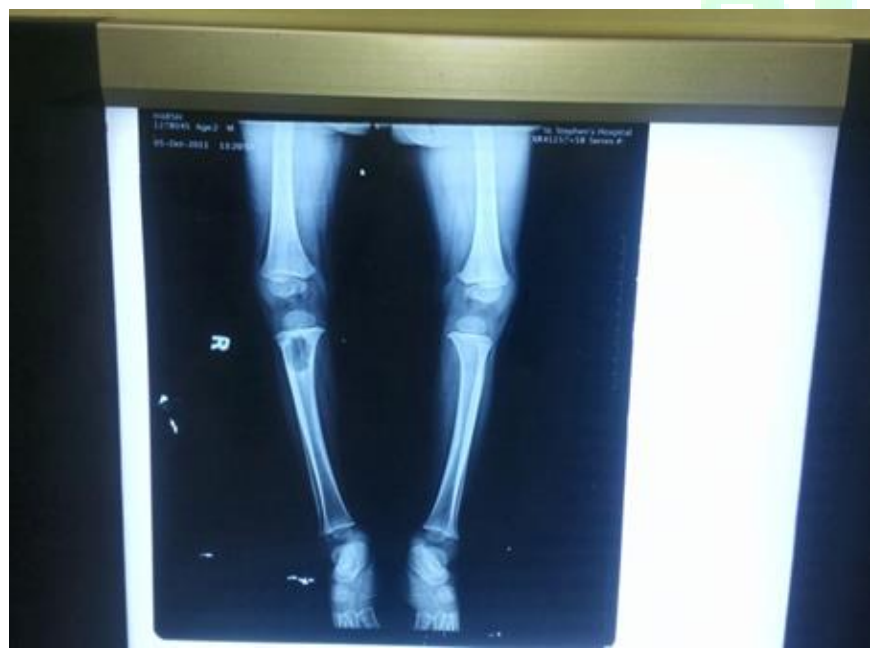

Figure 3: Punched out lesion in right tibia shown on X-Ray.

Then Patient was taken to private hospital in Delhi. Complaint of pain in legs alongwith lytic lesions in proximal tibia. Again biopsy of proximal tibia ---bone biopsy from Rt. proximal tibia--focus of non-caseating granulomatous osteomyelitis.

AFB Culture (AFB- Acid Fast Bacillus) --negative for AFB.

Biopsy from same site reveals---evidence of chronic inflammation --probable granulomatous inflammation. But smear was negative for AFB. But ATT started in view of biopsy findings.

Patient was investigated for CBC, LFT \& Serum Calcium (S. Calcium) level.

$\mathrm{Hb}($ haemoglobin $)=9.5$ gm \%; TLC (total leucocyte count) =9100/cumm; DLC (differential leucocyte count)-P-40/L58.

S. Calcium $=10.5 \mathrm{gm} \%, \mathrm{~S}$. ALK PO4 =315 IU/L

\section{Summary}

Patient presented with complaint of yellowish discoloration of skin \& sclera (icterus ++, per abdomen-liver--3 $\mathrm{cm}$ and tender, spleen - not palpable)-no obvious cause of hepatitis established.

So it attributed to ATT (taking-8-9 months of ATT-so ATT stopped).

For polyuria, S.ADH level were found to be low. So minrin spray was started.

After 1 month, no significant decrease in S.ALK PO4 levels. Urine output slightly decreased.

Patient was having osteolytic lesions in various bones of body and also started developing punched out lesions of scalp which were relatively more rapid and aggressive. So inspite of ATT osteolytic bony lesions, issues of LFTs remained as such.

Punched out lesions in skull (bony defect palpable). Even bony defect palpable also in right forearm.

Per Abdomen-Distended, Liver--4-5 cm, tender, firm, sharp leafy margins.

Icterus ++ .

Polyuria less but still present (on regular minirin spray --2 sprays/day).

Now summarizing --systemic involvement (hepatitis, punched out lesion in various bones of body including skull).

Diagnosis- Histiocytosis - X - with hepatitis with central diabetes.

X-Ray --shows--multiple radiolucent focal lesions noted in visualized skull bone [Figure 1] left humerus [Figure 2] \& right tibia [Figure 3] suggestive of histiocytosis.

USG (ultrasonography) Abdomen---hepatomegaly, Enlarged swollen pancreas (? Pancreatitis)

(S.Amylase/Lipsae-wnl -within normal limts), over distended bladder.

Now biopsy from punched out lesion --- tennis racket appearance.

MRI brain shows --destruction of sella turcica, damaging pituitary stalk.

So Traid of central diabetes insipidus / calvarial skull defects / - well fits into H.S.Triad.

Hepatitis along with above findings suggestive of langerhans cell histiocytosis.

So this diagnosis was made in advanced stage of disease.

\section{Discussion}

Child's chance of recovery (prognosis) and choice of 
treatment depend on the stage of child's disease (whether it is just in the bones, called localized disease, or has spread to other places, called disseminated disease). It will also depend on how do the cells look under a microscope, the child's general state of health, and his or her age. ${ }^{[1]}$

This condition is treated with steroids, which suppress immune function. Depending of the extent of disease, children may need further treatment including chemotherapy drugs, small doses of radiation therapy, or surgery. ${ }^{[1]}$

Single-system LCH may disappear of its own without any treatment. In some children, treatment such as surgery and corticosteroids (such as prednisolone) may be used. ${ }^{[9]}$ Multi-system LCH is usually treated with chemotherapy and corticosteroids. The length of treatment varies from child to child. ${ }^{[9]}$

\section{Conclusion}

This case had all the typical findings (symptoms \& signs), but even then it took considerable time to come to the correct diagnosis of advanced stage of langerhans cell histiocytosis. Though presenting rarely, this case was interesting enough to discuss.

\section{References}

1. http://www.histio.org

2. http://emedicine.medscape.com

3. Sellari-Franceschini, S.; Forli, F.; Pierini, S.; Favre, C.; Berrettini, S.; Macchia, P.A. (1999). "Langerhans' cells histiocytosis: a case report". International Journal of Pediatric Otorhinolaryngology 48 (1): 83-7. doi:10.1016/S0165-5876(99)00013-0. PMID 10365975.

4. Aricò, M.; Girschikofsky, M.; Généreau, T.; Klersy, C.; McClain, K.; Grois, N et al (2003). "Langerhans cell histiocytosis in adults: Report from the International Registry of the Histiocyte Society". European Journal of Cancer 39 (16): 2341-8. doi:10.1016/S0959-8049(03)006725. PMID 14556926.

5. Windebank KP, Nanduri V. Langerhans Cell Histiocytosis. Arch Dis Child. 2009 May 19. [Medline].

6. Egeler RM, van Halteren AG, Hogendoorn PC, Laman JD, Leenen PJ. Langerhans cell histiocytosis: fascinating dynamics of the dendritic cellmacrophage lineage. Immunol Rev. 2010 Mar. 234(1):21332.[Medline].

7. https://my.clevelandclinic.org

8. Satter EK, High WA. Langerhans cell histiocytosis: a review of the current recommendations of the Histiocyte Society. Pediatr Dermatol. 2008 May-Jun. 25(3):291-5. [Medline].

9. http://www.macmillan.org.uk

Copyright: (C) the author(s), 2019. It is an open-access article distributed under the terms of the Creative Commons Attribution License (CC BY 4.0), which permits authors to retain ownership of the copyright for their content, and allow anyone to download, reuse, reprint, modify, distribute and/or copy the content as long as the original authors and source are cited.

How to cite this article: Arora J, Mehta P, Roy VK, Sharma V, Kumar A. A Case of Diagnostic Dilemma - LCH. Asian J. Med. Res. 2019;8(3):PH04-PH07.

DOI: dx.doi.org/10.21276/ajmr.2019.8.3.PH2

Source of Support: Nil, Conflict of Interest: None declared. 